\title{
Joaquim Mir y la tienda de juguetes: microhistoria de un retrato
}

\section{Joaquim Mir and the Toyshop: microhistory of a portrait}

\author{
Oriol VAZ-Romero Trueba \\ Universidad de Barcelona \\ ovaztrueba@gmail.com \\ Esther AlsinA-Galofré \\ Universidad de Barcelona \\ alsinaesther@gmail.com
}

Recibido: 12 de enero de 2015

Aprobado: 14 de diciembre de 2015

\begin{abstract}
Resumen
¿Puede un retrato pictórico suscitar un ejercicio de microhistoria? Nuestra investigación tratará de aportar una respuesta positiva a esta cuestión, analizando para ello uno de los pocos retratos del pintor postimpresionista Joaquim Mir Trinxet, fechado en 1926. El protagonista representado no es otro que el suegro del pintor, Antoni Estalella i Trinxet, un insigne personaje de Vilanova y la Geltrú (Barcelona) que vivió entre dos siglos. La obra está ambientada en la tienda de juguetes de la familia, convirtiéndose así en una de las escasas pinturas que han captado el interior de una juguetería en la España anterior a la Guerra Civil. Gracias a los trabajos de archivo realizados, este artículo reúne diversos documentos inéditos que permiten reconstruir no sólo la vida del retratado, que llegó a ser corresponsal de Francisco Pi y Margall, sino también el ambiente social, artístico y comercial de Vilanova, en un período que abarca desde la década de 1870 a la primera mitad del siglo XX, en plena "Edad de Oro" de la industria juguetera. Es esta una propuesta de metodología historiográfica cuyo recorrido comienza en el oficio arcaico de la tonelería para desembocar al fin en los albores del comercio moderno de juguetes.
\end{abstract}

Palabras clave: Joaquim Mir, pintura española, juguetes, microhistoria, siglo XX.

Vaz-Romero Trueba, O., Alsina-Galofré, E. (2016): Joaquim Mir y la tienda de juguetes: microhistoria de un retrato. Arte, Individuo y Sociedad, 28(1) 121-138

\begin{abstract}
Can a pictorial portrait inspire a micro-history exercise? Our research will try to bring a positive answer to this question by assessing one of the few portraits by the post-Impressionist painter Joaquim Mir Trinxet dating back to 1926. The main depicted character is none other than the painter's father in-law, Antoni Estalella Trinxet, a well-known person in Vilanova y la Geltrú (Barcelona) who lived between two centuries. The painting is set at the family's store. Therefore it became one of the rare masterpieces showing the inside of a toyshop in Spain's pre-civil war period. Thanks to the research carried out at local archives, this contribution brings together many unpublished documents. The latter allow us to reconstruct the life of the portrayed man, who became Francisco Pi y Margall's correspondent, but also the Villanova's social, artistic and commercial environment, in a period spanning from the 1870 s to the early 20 th century, during the "Golden Age" of the toy industry. These pages mean to be a historiographical methodology proposal whose origins are set at the archaic craft of cooperage leading finally to the dawn of toy's modern trade. Keywords: Joaquim Mir, spanish painting, toys, microhistory, $20^{\text {th }}$ Century.
\end{abstract}


Sumario: 1. "Allí hay almas vivas, con fondo transitorio y fondo eterno", 2. Antoni Estalella Trinxet: atisbos de un patriarca vilanovino, 3. "El brazalete moderno" o el bazar de los juguetes, 4. Un Mir desconocido: yerno, retratista y etnógrafo romántico, 5. La historia del arte: un camino por recorrer. Referencias.

Este artículo recoge resultados de la investigación: 1) BRAC_Barcelona: Research, Art, Creation, con sede en la Facultad de Bellas Artes de la Universidad de Barcelona, grupo de investigación consolidado y financiado por la Agencia de Gestión de Ayudas Universitarias y de Investigación de la Generalitat de Cataluña (AGAUR), referencia 2014 SGR-5-GRC. 2) Proyecto de investigación fundamental no orientada El rostro humano: identidad y parecido. Referencia HAR2010-20661/ARTE, financiado desde 2011 a 2014 por el Ministerio de Economía y Competitividad.

\section{1. «Allí hay almas vivas, con fondo transitorio y fondo eterno »}

Ha transcurrido más de un siglo desde que Miguel de Unamuno hablase por vez primera de « intrahistoria » en su ensayo En torno al casticismo (1895); y lo hacía con estas palabras: "Penetrad en una de las viejas ciudades amodorradas en la llanura, donde la vida parece discurrir calmosa y lenta, [...] allí dentro hay almas vivas, con fondo transitorio y fondo eterno y una intrahistoria" (Unamuno, 1967: I, 811). Por aquel entonces, Unamuno abogaba por una historia "con minúsculas", centrada en el individuo y en su destino particular, para así tratar de clarificar la complejidad del mundo que le rodea. Parece poco probable, sin embargo, que Unamuno quisiera circundar el océano de la Historia "con mayúsculas" a base de simples retales humanos. Fueron historiadores como Giovanni Levi y Carlo Ginzburg quienes impulsaron el término moderno de microhistoria como método válido de investigación de la historia social, junto a Georges Duby y Philippe Ariès. Aunque en la actualidad resulta más familiar para antropólogos sociólogos, dicho enfoque puede fructificar en toda clase de terrenos históricos, tales como el coleccionismo artístico, la historia de los juguetes y la cultura material de la infancia; temas, éstos últimos, que conforman el entramado original del presente estudio.

La pintura de Joaquim Mir Trinxet (1873-1940) titulada Retrato de Antoni Estalella $i$ Trinxet (1926) es una de las escasas representaciones que se conocen de una tienda de juguetes de principios del siglo XX en España [fig. 1]. Asimismo, la personalidad del retratado y la atmósfera de la juguetería confieren al cuadro un carácter hogareño, poco frecuente en la producción del artista barcelonés. Estos elementos, de por sí llamativos, apenas han despertado la atención de los estudiosos (MAM, 1972. Jardí, 1975. Jardí: 1989. Miralles, 2006), pero constituyen un sustrato prometedor para un ejercicio de microhistoria al más puro estilo unamuniano. Una tarea de esta naturaleza nos lleva a dedicar una atención especial a la biografía del retratado, a su relación con el artista, a reparar en los elementos más cuidados del cuadro, como los juguetes que emergen del sombrío fondo. La microhistoria requiere entrelazar múltiples fuentes iconográficas, como estampas, pinturas populares o ilustraciones de libros. También exige consultar documentos de variada tipología: tarjetas de visitas, actas de bautismo y defunción, documentos notariales y hojas de patentes, contribuciones industriales, prensa, cartas y fotografías personales. La suma de tales legajos permiten recomponer así segmentos de una vida y de unas formas culturales en un momento dado. Como sostiene el historiador Michel Manson, "este procedimiento permite una historia total, económica, social 
y cultural, sobre la que fundamentar un nuevo saber en el cruce de varios caminos epistemológicos" (Manson, 2005: 130). Con este retrato pintado por Mir se nos brinda la oportunidad de adentrarnos en el lienzo, de situarlo, siguiendo a Unamuno, en una de esas "viejas ciudades amodorradas", no ya de la llanura, sino de la costa mediterránea: la Vilanova pesquera de 1920, donde también allí la vida parecía "discurrir calmosa y lenta", aunque repleta de almas vivas; almas como la de Antoni Estalella y los suyos.

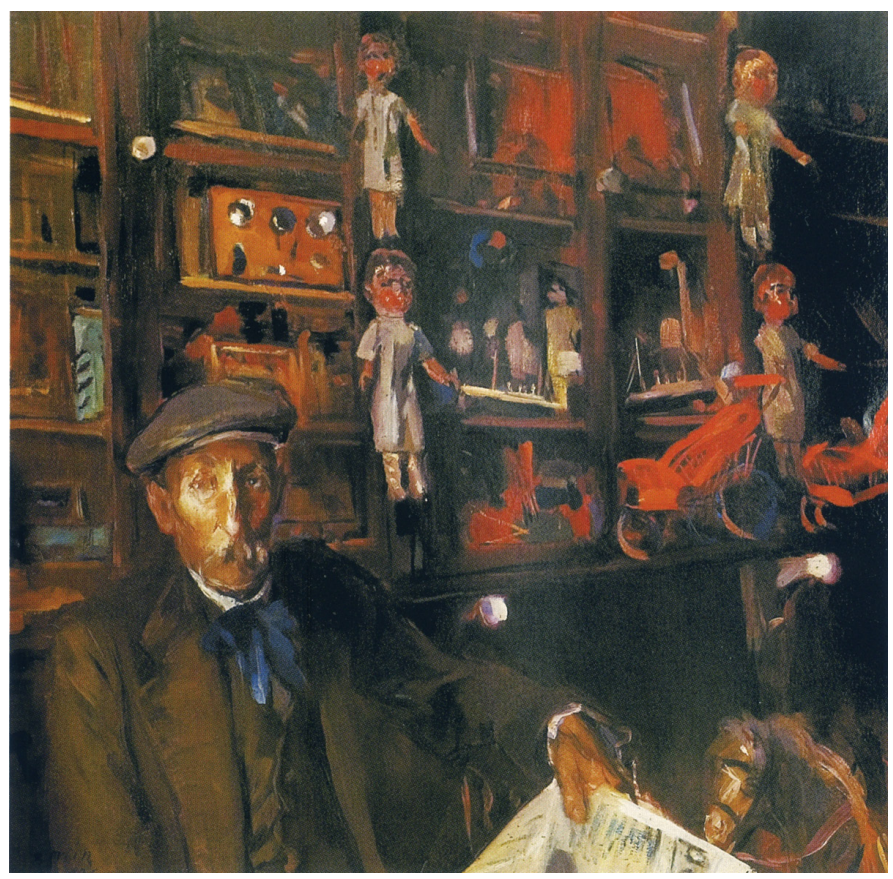

Figura 1.

\section{Antoni Estalella Trinxet: atisbos de un patriarca vilanovino}

Reconstruir el linaje del retratado no resulta tarea fácil a tenor de la frecuente repetición de antropónimos en la línea familiar de los Estalella. Hasta donde hemos podido explorar, los antepasados de Antonio Estalella Trinxet trabajaron de toneleros en las tierras del Alt Penedès desde finales del siglo XVII. Este dato nos remite al menos al nombre de Pau Estalella, nacido hacia 1687. Trabajaba como barrilero junto a su hermano Ramón, en el vecino municipio de Vilafranca, donde la tradición vinícola había permitido el auge de este oficio desde la Baja Edad Media (Mas Perera, 1932: 91. Virella, 1978: 205. Bolòs, 2000: 49). Aunque por aquel entonces no parece que existiera un gremio de boteros plenamente constituido, prosperaban los oficios derivados del cultivo de la vid, haciendo de ello una sólida tradición para algunas familias, como los Martorell o los Estalella (Massanell, 1984). En los albores del siglo XIX, la bonanza de la tonelería en Vilafranca se debió, por un lado, a un incremento del cultivo de la viña para una elaboración más específica de vinos y licores, y, por el otro, al aumento de la exportación como consecuencia de la crisis francesa de la filoxera, que hundió su sector 
vitivinícola y tonelero a mediados de la década de 1860 . Este crecimiento propició que el linaje Estalella obtuviese por fin una situación económica lo bastante holgada como para que su último heredero, Antoni, dejase el oficio centenario de su prosapia.

La línea familiar más antigua, en Vilafranca, es la unión de los Estalella con los Ballester (1752-1763), seguida de los Estalella y Bernadas (1777 y 1850), ya situados en Vilanova, en una casa junto a la playa, donde muchos toneleros solían tener sus almacenes. Por último, se produce la unión entre los Estalella y los Millé (1810-1862). El 17 de diciembre de 1851, Joaquim Estalella Millé — tonelero en su juventud y tal vez comerciante de baratijas en sus años canos, como su padre, un tal Antoni Estalella casado con Antònia Millé - desposaba a una joven de Barcelona llamada Maria Trinxet Cassas, hija de Joan Trinxet y Eulàlia Cassas. De este matrimonio nacieron tres vástagos. Según el Archivo Parroquial de la iglesia de Sant Antoni Abat, el 9 de octubre de 1852 nacía el primogénito, Antoni Estalella Trinxet, protagonista del lienzo de Mir. El 5 de julio de 1854 nacía su hermana María, que murió tristemente a los dos años. Finalmente, el 16 de octubre de 1856, llegaba al mundo la pequeña Clàudia.

Aunque no disponemos de los documentos del enlace entre Antoni Estalella Trinxet y Dolors Asbert Aymar, el matrimonio tuvo tres hijas: la mayor, Maria, nacida en 1881 y con la que se casará el pintor Joaquim Mir en 1921. Vinieron luego Antònia (1885) y Claudia (1890), todas ellas traídas al mundo en el piso de la Calle Comercio 1. El detalle no es baladí, pues es precisamente en los bajos de esta vivienda donde se ubica la tienda de juguetes y quincalla de Antoni Estalella.

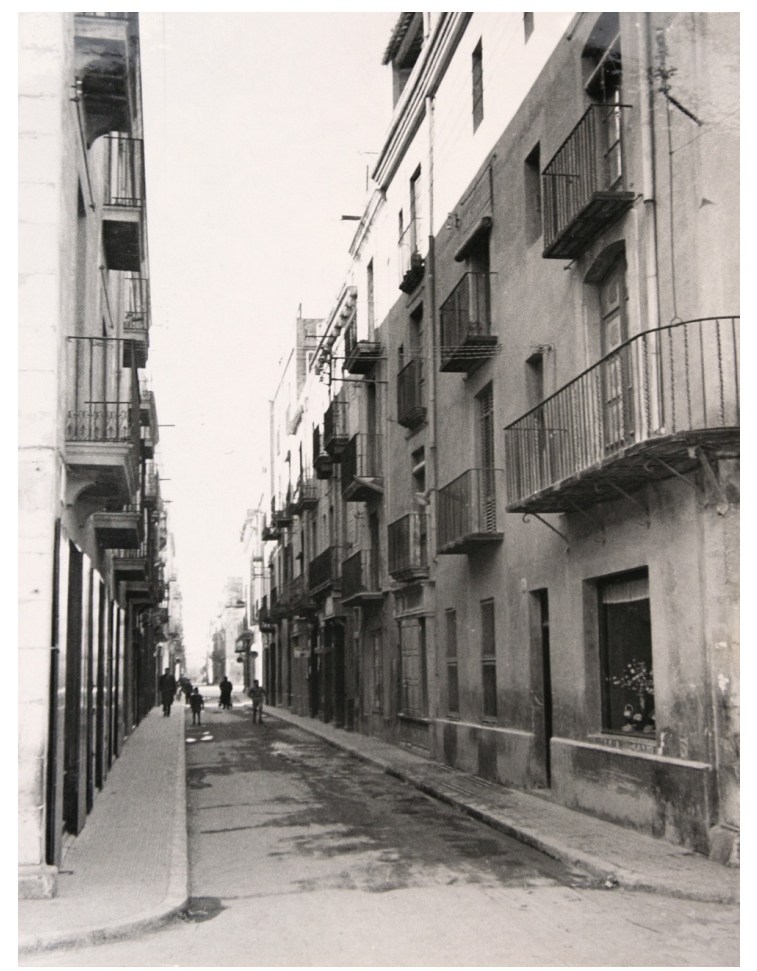

Figura 2. 
De la vida del suegro de Joaquim Mir no poseemos demasiadas noticias, salvo algunas actas municipales y reseñas de terceros. Podría decirse que pasó su vida en su tienda de juguetes y quincalla, aunque, por otra parte, estaba siempre dispuesto a participar en todos los acontecimientos ciudadanos. Durante los años de 1889 y 1893, y más tarde, entre 1899 y 1903, prestó sus servicios como concejal del Ayuntamiento de Vilanova. En 1904 cesó su último cargo municipal como regidor interino (Defensa, 1927; Puig Rovira, 2003: 113). Durante sus más de diez años de trajines "políticos", pero también en cualquier otra ocasión propicia, Antoni Estalella fue un acérrimo valedor de las comisiones que organizaban las fiestas mayores, los carnavales y actos de protocolo señalados en el calendario social de la villa. No sorprende que fuese nombrado presidente vitalicio de las fiestas populares y cívicas. Nunca faltó a las inauguraciones y reuniones del Consistorio, interviniendo a menudo en los plenos con soflamas propias de un apasionado patricio romano. En tono mordaz lo enuncia su amigo, el pintor y grabador Enric-Cristòfol Ricart: "Mir es ya tan popular [en Vilanova] como su suegro, el felizmente incomparable Estalella. Está bien que existan patricios como Estalella, uno en cada pueblo, pero no más de uno" (Ricart, 1922).

Las actas de los plenos locales guardan páginas memorables de sus parlamentos, enérgicos y razonados, siempre pavonados con palabras de aliento y optimismo. Encontramos su nombre entre los componentes del Sindicato de Regantes para la construcción del pantano de Foix, junto al ingeniero del proyecto, Hermenegildo Gorría, con el propósito de "llevar a feliz término la idea tanto tiempo iniciada de convertir nuestras tierras de secano en campos de regadío" (Fomento, 1907. Veu, 1921). Asimismo, como miembro de la Junta del Cementerio "tomó ese lugar como una joya de su especial predilección. [...] Frente a ilustres comitivas que visitaron el Campo santo figuraba el amigo Estalella para historiar los proyectos de la Junta, y al lado de los Ilustrísimos Prelados, veíamos a nuestro 'Cicerone' dando detalles históricos de todas y cada una de las sepulturas [...]. Los cipreses, arbustos y flores de ese reposado lugar podrían referirnos los cuidados innúmeros que recibían de su asiduo visitante, y les quitaba las hojas secas y las ramas torcidas, para que su perfume se confundiera con la oración que subía hasta el cielo" (Defensa, 1927: 2).

Siendo concejal, Estalella participó en los arreglos del homenaje al político, poeta y coleccionista vilanovino Víctor Balaguer, fallecido en 14 de enero de 1901, formando parte de una corporación constituida por miembros municipales y de la BibliotecaMuseo, fundada por el propio Balaguer en 1884. Estaba resuelto a "construir una sepultura y monumento que guarden los preciados restos del gran poeta y su virtuosa esposa, y perpetúen, al par que la gloria del llorado poeta, la gratitud del pueblo" (Balaguer, 1901). En el otoño de su vida pública, hacia 1910, Estalella seguía alentando proyectos como el urbanístico iniciado en Ribes Roges por Agna Raventós de Sauró, presidenta de l'Empar de Santa Llúcia. En 1917, siguiendo consejo de nuestro insigne vilanovino, el arquitecto municipal Josep M. Miró Guibernau quiso reformar la tipología de urbanización convirtiéndola en una ciudad-jardín con paseo marítimo. Fue esta una ambición de Estalella truncada tras su muerte por el nuevo Plan de Ordenación de 1967, que permitiría densificar las edificaciones en primera y segunda línea de mar, acarreando el derribo de la mayor parte de las casas modernistas originales. Se sabe de otros muchos proyectos en los que participó "entre bastidores", como la prolongación de la Rambla 
de la Pau, la inauguración del Castell de La Geltrú, de la Rambla Samà y de la calle Pi i Margall (Llorens Artigas, 1918). Pero todo ello se resume con luminosa claridad en el epitafio publicado por el periódico republicano Democràcia, donde define a Estalella como paladín del progreso de Vilanova, por la que sentía "un amor rayano al fanatismo" (Puig Rovira, 2005: 282).

Por alguna de sus cartas, sabemos de sus simpatías hacia el modelo federalista, lo que ha llevado a relacionarlo con la figura de Francisco Pi y Margall (1824-1901), presidente de la Primera República entre el 11 de junio y el 18 de julio de 1873 (Jutglar, 1976: 1104). De hecho, en noviembre de 1894, Estalella escribía una carta a Pi y Margall requiriéndole un prólogo para un nuevo manifiesto del partido federalista de Vilanova y la Geltrú. El diario El Nuevo Régimen publicaba desde Madrid la enardecida respuesta del depuesto presidente de la Primera República, firmada el 11 de diciembre y dirigida al propio Estalella: "Me pedía usted un prólogo para la publicación que intenta. Sírvale á usted de prólogo esta breve epístola, tan corta como grande es el afecto que le profesa su amigo y correligionario" (Pi Margall, 1895).

Se ha sugerido también que Estalella "era un ateo explícito y desvergonzado, que se asomaba provocativamente al balcón comiendo morcillas al paso de la procesión de Viernes Santo" (Pi de Cabanyes, 2006: 44). Sin embargo, abundan los testimonios a favor de su piedad religiosa, verbigracia de su especialísima devoción a San Antonio Abad, patrón del municipio. No en vano dejó escrito en su honras funerarias que dejasen descubierta y bien iluminada la imagen del monje eremítico, dejándolo a la vista de todos en el altar mayor de la concurrida "Catedral penedesenca", altar que fue demolido por los republicanos en 1936 (Veu, 1927).

Estalella murió con setenta y cuatro años de una aguda enfermedad, el 10 de febrero de 1927 (Veu, 1927). Pero más dolor hubiera sentido al ver los estragos innúmeros que la guerra causó en su amada Vilanova. De hecho, intentó apartarse del fragor anticlerical y "siempre había lamentado que la comisión encargada de las Fiestas Mayores no se ocupase un poco más [...] de la procesión que sale de nuestra Arciprestal para las fiestas de la Virgen de las Nieves" (Defensa, 1927). Estalella había vivido la política con vigor, pero nunca fue un acérrimo partidista. Según parece, trató de guiarse más bien por principios morales innatos: "en sus adentros poseía otro tipo de idealismo, superior, que le hacía pensar y actuar con una rectitud de consciencia ennoblecedora", próxima a los postulados de la célebre encíclica Rerum Novarum, firmada por León XIII en 1891. Quizá por eso nuca pudo esconder su amor por el arte sacro de su ciudad, "al que prestaba todo su entusiasmo para que las manifestaciones del culto divino revistiesen del esplendor debido [...] y quiso morir recibiendo los Santos Sacramentos para corresponder al sentimiento que había exteriorizado en su parroquia”. Según un apunte biográfico inédito, que suponemos escrito por el archivista Cristòfol Escofet para algún diario local, Estalella estuvo siempre más preocupado por embellecer Vilanova que por las ventas de su tienda de quincalla y juguetes. Soñaba con una villa capaz de causar admiración en propios y extraños, por lo que, viejo y enfermo, todavía dedicaba una hora de sus quehaceres diarios a recorrer las calles observando su estado de conservación y forjando nuevos planes para convertir las plazas en suntuosos jardines públicos (Puig Rovira, 2011). 


\section{3. « El brazalete moderno » 0 el bazar de los juguetes}

La mirada se nos va ahora hacia el abarrotado interior del cuadro de Mir. Fue una tienda de juguetes y fruslerías, pero también fue el cuartel general de los Estalella. Apostado entre la calle Comerç y la calle San Gregori [fig. 2], el establecimiento era además la puerta de su casa, pues la familia vivía en el piso de arriba, al más puro estilo de los comercios medievales. El edificio, sobrio pero sólido, sigue en pie frente al palacete de la familia Cabanyes, comerciantes ennoblecidos por Carlos IV, casa natal de Manuel de Cabanyes Ballester, uno de los primeros poetas románticos españoles. La tienda desemboca también en la plaza de las Verduras o de las Coles, donde se montaba el mercado semanal del municipio y se celebraban diversas ferias agrícolas.

La tienda podría haber pertenecido a su abuelo Anton Estalella Bernadas (1782?1856), si bien no podemos asegurarlo con certeza, pues nada nos dicen al respecto los libros de contribuciones industriales y comerciales de la primera mitad del siglo XIX (Puig Rovira, 2006: 36). Parece que el negocio comenzó a funcionar como juguetería en mayo de 1878, figurando Antoni Estalella Trinxet como único contribuyente [fig. 3]. Aunque no se conserva la relación de altas de ese año, al estudiar los legajos de ejercicios anteriores, ni en la Sección 6 -que correspondía a las tiendas de juguetes o baratijas - ni en las demás secciones hay rastro de la tienda de Estalella. En cambio, sí constan otras jugueterías, algunas de las cuales se encontraban también en la calle Comerç. Es el caso de la tienda de Antonio Gibert y de Clara Miró de Janini. Como vendedores de juguetes, también aparecen entre 1875 y 1890 los nombres de José Pi Solà, apostado en la calle de Sant Pere, el de Escofet, en la calle Sant Gregori, y los de Juan Bautista Mascaró y Antonio Arboig, ambos en la calle Progrès. Vendrá en 1897 la familia Ferreras con su pequeño bazar de la calle Mayor, conocido años más tarde como "Cal 65" o "Cal Mut", que se trasladó a la calle Progrès, hoy de los Caputxins.

Haciendo honor a su nombre, la calle Comerç y sus aledaños eran la arteria comercial de la ciudad. En la década de 1890, encontramos, entre otros muchos propietarios, varios hojalateros, vendedores de alfombras, tiendas de géneros, tablajeros, silleros de madera y relojeros. La calle conectaba la Vilanova antigua, circundada por casas principales de finales del siglo XVIII como la de los Cabanyes, con la zona pesquera y portuaria. Con todo, corrían tiempos difíciles para los comerciantes de Vilanova. Los años de guerra con Cuba estaban a punto de desembocar en una trágica derrota que afectaría de lleno a todos aquellos vilanovinos que habían mantenido negocios desde hacía más de un siglo con la isla caribeña y América continental (Ortiz Domènech, 1998). 


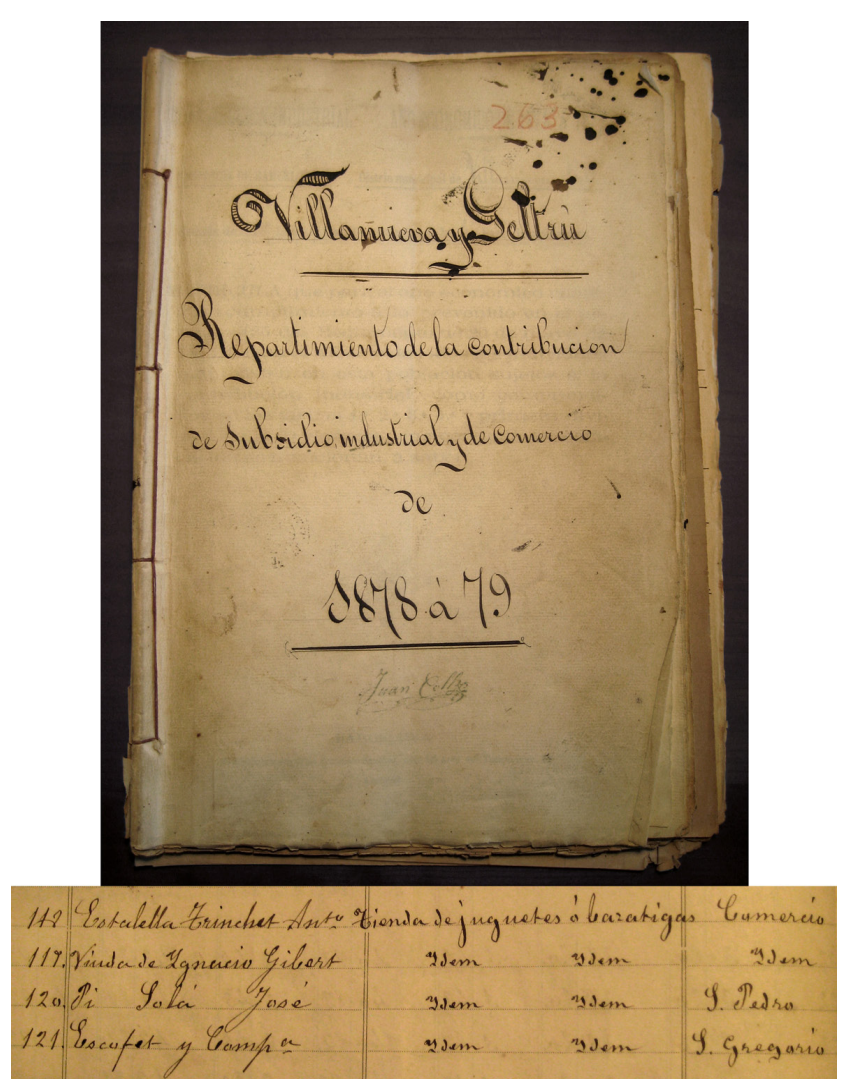

Figura 3a. (sup.) Figura 3b (inf.).

A pesar de todo, la tienda de juguetes y quincalla de Estalella fue una de las más longevas de la ciudad. Tras su muerte, los libros de 1927 y de los años siguientes señalan que el negocio de juguetes de Comerç 1 seguía pagando con regularidad sus contribuciones -que pasaron de 43 pesetas mensuales en 1878 a 116 en la década de 1930 - . Al inicio de la Guerra Civil, los legajos atestiguan la existencia de seis jugueterías, aunque la del patriarca Estalella subsistía en solitario en la calle Comerç. En el legajo de 1947 se produjo una errata en el registro que el funcionario municipal corrigió con una "a" al nombre del propietario: "Estalella Trinxet, Antonio(a)". Sabemos así que la tienda de juguetes pasaba a nombre de la segunda hija del patriarca, Antonia, constando ya como "mercería". Diez años después, el 6 de marzo de 1958, el número de orden 322 certificaba el cierre definitivo de la tienda, mientras que otras cinco jugueterías siguieron existiendo en Vilanova, entre ellas, la de "Cal 65", que cerró en el año 2000.

Durante los ochenta años de existencia (1878-1958), la tienda se conocía popularmente como "El brazalete moderno", tal vez en honor a alguna conocida quincallería barcelonesa ochocentista, borrada como tantas por causa de la crisis económica - $\mathrm{O}$ debido a que, ya entonces, los gustos del público cambiaban, poniendo sus preferencias en nuevos géneros (Corredor-Matheos, 1981: 63. Carrera Pujal, 1961: 159. Mestre, 
1999: 98) - Es cierto que Antoni Estalella vendía en su tienda muchas más cosas que juguetes, como todas las "tiendas de juguetes y baratijas". Tenía mantillas y abanicos, pipas, caretas, hojas de aleluyas, radios, perfumes e incluso coronas de flores mortuorias y el "célebre revelador monetario Wirpse para conocer la moneda falsa". Este invento, que Estalella se gloriaba de vender, es difícil de reseguir en las hemerotecas, aunque, a juzgar por la invasión de moneda falsa de finales de siglo, no es de extrañar que se convirtiese en un objeto codiciado. Ya acusa Azorín a los carlistas de haber inundado España de monedas falsas (Azorín, 1922). Informadores franceses así lo confirman y llegan incluso a referirse al invento vendido por Estalella como un "lápiz especial, compuesto químico, que sirve para reconocer la falsa moneda, vendido en Barcelona" (Engel, 1892: 135-136, n. 2).

Sin embargo, con el nuevo siglo y la leve recuperación económica de la burguesía vilanovina, los Estalella priorizaron la venta de juguetes y regalos. Tenían sobre todo juguetes de hojalata y madera, así como peonzas, canicas de todas las medidas, las clásicas pepas de cartón, cromos de los héroes de cómic, aros, caballitos con ruedas o balancín, barcos y vehículos de madera u hojalata, todo siempre a un precio asequible. Al salir del colegio, todo eran deseos de hacerse con los cromos que faltaban para completar la colección o de adquirir el último modelo de coche de Payá o Rico. Las niñas menos favorecidas se contentaban con acunar una muñeca de papel maché, como las "peponas", de caras redondeadas y fisionomía helénica, mientras que las más favorecidas, en plena postguerra, comprarían en El Brazalete Moderno algún prohibitivo modelo de Mariquita Pérez. Por eso las chiquillas tarareaban de memoria la canción del maestro Jacinto Guerrero, el autor de La Rosa del Azafrán (1930): "Mariquita Pérez, para las mujeres, / desde que son niñas, retoños de hogar; / Mariquita Pérez iqué elegante eres! / Pues el mes que viene he de serlo más" (Martín Gaite, 1987). A pesar de que los juguetes del comercio habían sido siempre artículos de lujo para los niños de las clases trabajadoras, siendo los juegos callejeros « sin juguetes » los más recordados, lo cierto es que el negocio juguetero daba sus pequeños beneficios (Targa, Barbacil, 2006). Sorprende que, en una localidad como Vilanova, con tan sólo 12.000 habitantes en 1905, tuviera en su casco histórico más de cinco quincallerías vendiendo juguetes industriales, capaces de rivalizar en ventas con los puestos ambulantes que se reunían en las plazas de la ciudad durante las ferias de otoño y Navidad, según lo representa Ricart en un dibujo de 1934 (Borràs, 1993: 103). 

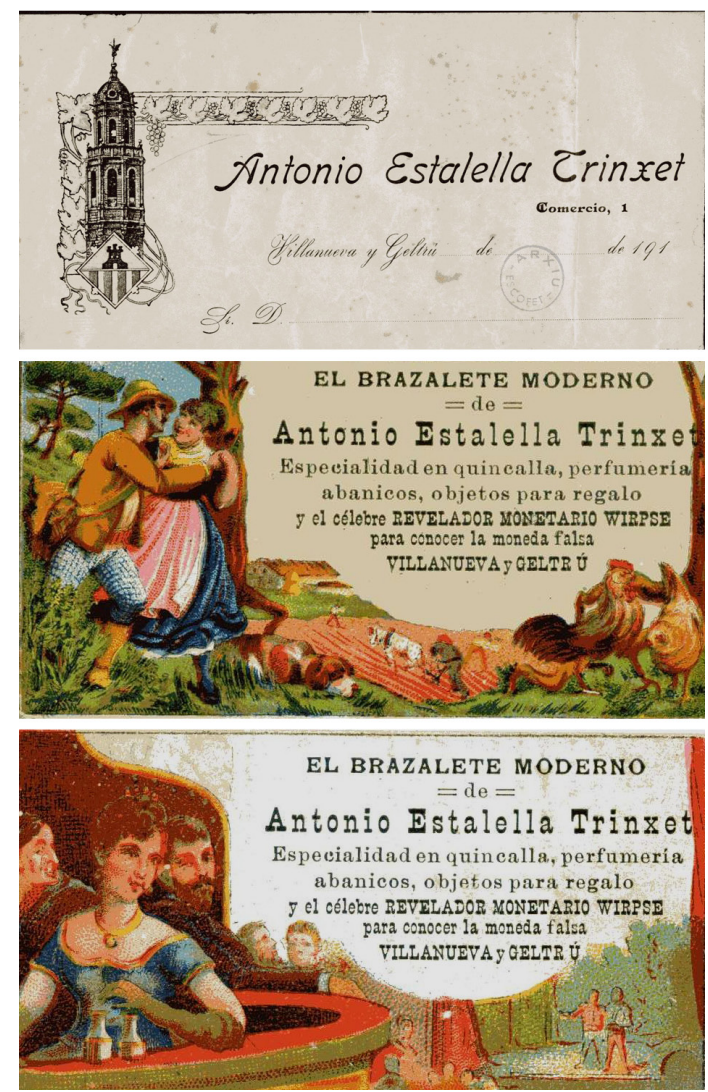

Figura 4.

Como en todo lo que se refería a Vilanova, Estalella quiso mimar en grado sumo la imagen de su comercio. Para ello, diseñó él mismo su "escudo de armas" y sus tarjetas publicitarias basándose en la silueta del campanario de la iglesia de Sant Antoni. También utilizó el logotipo en todos los encabezados de sus papeles comerciales: facturas, albaranes y cartas [fig. 4]. Dice La Veu de Catalunya en su necrológica de 1927: "toda su vida puede concretarse en este noble blasón que él escogió". Las ilustraciones de sus papeletas publicitarias reflejaban tanto la vida campesina tradicional, en un estilo similar a los grabados del vilanovino Enric C. Ricart, como la más sofisticada escenografía burguesa, plasmada en la imagen de un palco típico de los teatros finiseculares de Vilanova, como La Sala, construida en 1804, el Teatre Artesà (1857), el Tívoli Vilanovés (1860) o el Teatre-Cafè Apol-lo, inaugurado en 1878. Con estas papeletas, Estalella acaso querría sugerir que en su Brazalete Moderno podía encontrarse toda clase de artículos, desde los más simples y cotidianos hasta los más refinados.

Este "acreditado industrial" (Veu, 1927) resultaba un tanto pintoresco entre el estamento de tenderos de Vilanova. Su vocación filantrópica había convertido la tienda en un centro de reuniones sin igual. "Gozaba de una posición económica desahogada que le permitía vivir relativamente bien dentro de las ambiciones moderadas que entonces 
tenía la pequeña burguesía; en su tienda, consideraba más importante atender bien a los clientes y mantener un ambiente de relación y de tertulia que alcanzar un gran volumen de ventas" (Puig Rovira, 2006: 176). En una conversación telefónica mantenida en 2011 con Josep Mir, el hijo del pintor nos cuenta que E. C. Ricart, amigo íntimo de Mir, solía visitar a Estalella en su tienda de juguetes, "donde ambos dedicaban horas a despacharse a gusto con toda la ciudad. [...] Por eso la llamaban 'la tisora d'or', esto es, la tijera de oro". Como admite Josep Mir, antes de la llegada de su padre a Vilanova, El Brazalete Moderno había sido la base de operaciones para casar al célebre pintor, emparentado con el viejo Estalella por la vía de los Trinxet, con alguna de sus tres hijas.

\section{Un Mir desconocido: yerno, retratista y etnógrafo romántico}

Por todo ello, no parece casual que Mir decidiera retratar a su suegro en la tienda de juguetes, pues era este comercio su vida entera, el escenario donde mejor desempeñaba sus dotes sociales y donde mejor urdía los planes de reforma para la ciudad de sus amores. Las benditas "intrigas" acaecidas en El Brazalete Moderno dieron sus frutos, pues Maria, la hija mayor de Estalella, se casó el 17 de agosto de 1921 con Joaquim Mir Trinxet. Por diversas cartas, que se remontan a 1890, sabemos que durante las visitas de Mir a Vilanova anteriores a la gran ceremonia, el pintor se había hospedado varias veces en la residencia de la calle Comerç 1. Según parece, tenía buena relación con su viejo primo Antoni Estalella, "cuyo temperamento acogedor era proclive a la amistad con Joaquim Mir [fig. 5]. Estalella se mostraba orgulloso de tener entre sus familiares a un pintor de fama, que había estado en su casa varias veces" (Puig Rovira, 2006: 176). En una carta de 12 de abril de 1921, Estalella contesta a la pedida de mano de su futuro yerno, al que trata con paternal ternura (Estalella Trinxet, 1921). A pesar de algunas pistas publicadas (Jardí, 1975. Diario de Vilanova, 2003. Miralles, 2006), la vida de Joaquim Mir en Vilanova sigue oculta tras una celosía de silencios familiares. Se ha dicho de Mir que durante esos años, se transformó en "malabarista" al tratar de captar la vida y las fiestas de Vilanova. De hecho, los dos cuadros que representan las comparsas bailando en la plaza de las Coles fueron pintados desde el balcón de la vivienda de Antoni Estalella. La anécdota no es baladí, pues nos sitúa ya en el asunto más relevante de nuestra historia y también en el menos estudiado: la mirada nueva que Mir arrojó sobre los pequeños universos cotidianos de esa apacible ciudad pesquera.

Antes de llegar a Vilanova, "Mir había sido un trotamundos en busca de paisajes y de sí mismo. [...] Llegó a Mallorca, donde, sobrevolando la rivalidad con Santiago Rusiñol, supo forjarse un lenguaje propio y crear su mito particular al caer por un acantilado, donde pintaba" (Miralles, 2007: 20). De Mallorca fue a parar al Aleixar, en la provincia de Tarragona, para poder seguir los controles médicos que el Instituto Pere Mata de Reus le imponía, tras pasar allí casi dos años por desequilibrios mentales. Mir desarrolló entonces una pintura rayando la abstracción, de la que brotaría su fama internacional. Bajo los cuidados de su hermana y de su madre, se mudó con ellas a distintos pueblos del Vallès, como Caldes de Montbui, desde donde solía escribir a Estalella y cuyas campiñas le enfrentaron de nuevo con los problemas impresionistas de la luz (Cruells, 1994). Sin duda, al llegar a Vilanova para las nupcias con Maria Estalella, el entorno del pintor supo forjar una leyenda sobre su personalidad solitaria, esquiva y aburguesada; una leyenda avivada por todos aquellos que le visitaban, como el político Francesc 
Cambó, el escritor Josep Pla, el músico Pau Casals o el Abat de Montserrat, Antoni Maria Marcet, entre otros conocidos cuyas dedicatorias aparecen en el libro de visitas que el matrimonio colocaba a la entrada de su casa en el número 1 de la calle de Sant Josep (Mir, 1934. Pla, 1996: 146-147).

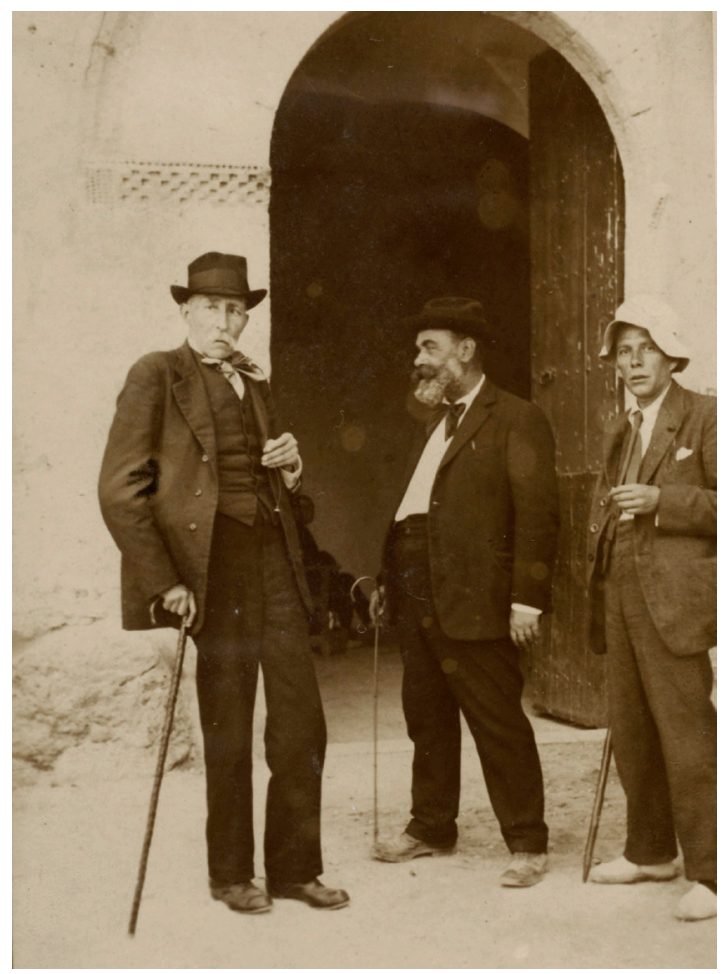

Figura 5.

Los cuadros pintados en Vilanova constituyen un diario personal del artista. En la intimidad de esas horas, el pintor sintió por vez primera el impulso de acercarse a las realidades más humildes y cotidianas. Sin abandonar su atracción por el paisaje —que sondeó de un modo nuevo en los caleidoscópicos fragmentos del jardín familiar-, Mir pintó las casas marineras, los pescadores, las remendadoras y los personajes de la lonja durante el corto período en que vivió con su esposa en una casita de la playa (Puig Rovira, 2006: 37), propiedad de los antepasados barrileros de la familia. Como el Kandinsky fascinado por la Rusia de sus antepasados, el pintor barcelonés representó la Vilanova de Estalella: un vergel preindustrial repleto de microhistorias, ajeno a la industrialización y a las amenazas políticas que despuntaban por doquier. Guiado por este impulso, pintó también a las gentes de los bailes populares - los cuadros del Foment Vilanoví-, así como varias personalidades de la ciudad. Si existe una huida antrópica en la etapa de sus grandes paisajes abstractivos, siguiendo la estética romántica del paisaje (Fontbona, 1999), Mir ensayó en Vilanova el género del retrato al más puro estilo cezanniano. Empezó con su madre y su mujer, atreviéndose después con figuras como el presidente del Foment Vilanoví, Lluís Carola Hugas, el violinista Werner, los escultores Alemany y 
Cañas, el pintor y arquitecto Francesc Ventosa o su amigo Ricart. Dichos retratos nunca fueron hechos por encargo. No hace falta recordar que nuestro cuadro es precisamente uno de los más destacados de esta serie, realizada entre 1920 y 1930, en la que Mir captó las tensiones entre la villa decimonónica, que no acaba de morir, y esa otra moderna que no acababa de nacer.

Con estos lienzos, Mir se había aventurado "hacia lo desconocido" (Miralles, 2007: 21), logrando un paisaje etnográfico de Vilanova. Según Josep Pla, el yerno de Antoni Estalella siempre tuvo en mente "el olor de las vendimias de Vilanova, el perfume de la vinaza y de los escobajos de la uva, de las portadoras, de las botas y toneles, el gusto de las bodegas frescales que flotaba en otoño sobre la población y sus alrededores" (Pla, 1996: 142). Quizá ese apego atávico a la tierra explica el destello de complicidad entre el pintor y el patricio vilanovino. Estalella debió ver en su yerno al demiurgo capaz de inmortalizar con vibrantes colores los rasgos más genuinos de su amada ciudad, nunca antes representada por un artista famoso. Por la misma razón, es probable que Mir quisiera pintar a su suegro en la tienda de juguetes, en su "base de operaciones", como tributo al hombre popular que fue, símbolo de una época que se perdía a pasos agigantados. Lo perfila elegante y con porte recio, semejante a un Dux renacentista. De rostro grave, sedente en su trono, sostiene el periódico abierto entre las manos, hilvanando planes venideros para su pequeña "república penedesenca".

La nueva sensibilidad pictórica de Mir le permitió reparar del mismo modo en las nimiedades de la infancia, sobre todo a partir del nacimiento de su hijo Josep, al que retrató a la edad de seis años. Según sostiene el escritor Luís Albalate, "el pequeño Pep fue el gran juguete para Mir" (Albalate, 1993: 81). En cuadros anteriores, ya había empezado a captar la silueta huidiza de los niños callejeros, jugando y paseando cerca de la playa, a la entrada de un comercio, o bien al retratar a uno de sus más jóvenes discípulos, el pequeño Salvador Masana (1924-2009). Pi de Cabanyes señala incluso que, por aquel entonces, Mir "tenía mucho de crío. Por eso le gustaba tanto la compañía de los niños". Su hijo Pep cuenta que, en ocasiones, su padre le compraba sobressorpresa: "Por un duro te daban uno, y por dos o tres duros un puñado, y te salían un silbato, una peonza, un muñeco, un cromo o cualquier otra cosa... Nos sentábamos en el bordillo, mi padre y yo, a mirar lo que nos había tocado. Y un amigo, pasando, comentó una vez en voz alta: 'No se sabe quién es más chiquillo, si el hijo o el padre..."' (Pi de Cabanyes, 2006: 51. Barral, 2001: 415).

Aunque el hijo de Mir no conoció a su abuelo, no pocas ocasiones tendría de adentrarse en El Brazalete Moderno, regentado en aquella época por la tía Antonia. Llama la atención que, habiendo objetos de toda clase a la venta, Mir escogiera el rincón de los juguetes como telón de fondo. Tal vez porque se deja arrebatar como Baudelaire, embobado frente a las jugueterías parisinas de 1853 (Baudelaire, 2005). El horror vacui que envuelve a Estalella en el cuadro se aprecia por igual en los grabados románticos de comercios y ferias jugueteras, como los que aparecen en los catálogos de ventas de la segunda mitad del siglo XIX. Los estantes pintados por Mir traslucen así la complejidad de un mundo en miniatura, fiel reflejo de esa "Edad de Oro" del juguete. Vemos barcos de vapor torneados y algún que otro coche de hojalata, como los de Rico y Payà. Otra rápida pincelada nos sugiere una cajita con figuritas de plomo, como las comercializadas por la casa Ortelli. Resaltan los carritos de muñeca, pintados de rojo, y las típicas formas contrahechas de las "pepas de deu", idénticas a las que se publicaron en el Catálogo de 
la Primera Exposición Nacional de Juguetes, celebrada en Barcelona (1914). En primer plano, junto a Estalella, Mir añade todavía un caballo de cartón como los que Antoni Penas Sardà había empezado a fabricar en 1892 y que el poeta Joan Salvat-Papasseit cantaría con tanta añoranza en sus versos de 1921 (Salvat-Papasseit, 1982).

Los juguetes pintados por Mir son productos de la floreciente industria catalana de principios del siglo XX, pero no son juguetes de lujo, como los que solían llegar de Alemania, Francia o Gran Bretaña. Responden todavía al ideal romántico del juguete semi-artesanal, mudo superviviente de una mecanización implacable. Los juguetes vendidos en quincallerías como la de Estalella se fabricaban en serie, sí, pero en talleres familiares, en los que no podía atenderse una demanda a gran escala ni con garantías de continuidad. Eran juguetes sencillos: caballos y muñecas de cartón, tambores y trompetas, un timbalero que tocaba como en la Fiesta Mayor al tirar de un hilo, soldaditos de estaño y un puñado de animalillos pensados para ocupar la panza de un Arca de Noé de madera; sin olvidar alguna que otra figurita articulada, producida en el torno de algún ebanista de barrio (Serra Pagès, 1926: 42). Sin embargo, los ochenta años de existencia del Brazalete Moderno y la apuesta del propio Estalella y de sus hijas por la venta de juguetes lleva a pensar que el catálogo de la tienda debió variar considerablemente a lo largo de su historia. El cuadro de Mir sólo nos otorga una instantánea — de hecho la única conocida - de lo que allí pudo llegar a venderse. No sería extraño que, tras la muerte del padre en 1927, las hermanas Estalella llegaran a despachar "sobres-sorpresa" como los que recuerda Josep Mir, así como los primeros juguetes de plástico, ya populares en España a finales de 1940 por su bajo coste y su gran variedad de formas (Pérez Valiente, 1946).

Del mismo modo que para fabricar juguetes se precisan dibujantes, modelistas, técnicos y costureros dotados de paciencia, destreza y amor al niño, para seleccionarlos y venderlos en una juguetería se requiere conocimiento del medio social, es decir, aquello que los niños y niñas de la ciudad más codician. Si el pensamiento del hombre se dulcifica mientras planea inventos con los que solazar a los chiquillos, también el modo de presentar esos juguetes en las estanterías de la tienda tiene algo de juego escénico. En el mercado juguetero español de principios del XX, la escala de precios era variadísima: desde los lujosos trenes, entretenimiento de los niños y del padre ingeniero; y desde la muñeca con cabeza de cera - verbigracia las de Pierrotti y Montanari, cuyos complementos costaban casi como el de la dama londinense mejor acomodadahasta llegar al coche humilde y la cunita sencilla vendidos en el número 1 de la calle Comerç. Se hace difícil concebir al patricio vilanovino colocando en su negoci, con aristocrático ademán, las frágiles y altivas muñecas de porcelana. En cambio, lo imaginamos adecentando a sus espurias hermanas, las tiesas peponas; esas que, según el poeta Salvador Pérez Valiente, "olían a húmeda ropa que se tiende en los patios sin sol, [...] tristes desheredadas, presencia en carne viva del antiguo, tosco, entrañable juguete ibérico!" (Pérez Valiente, 1946: 19).

\section{La historia del arte: un camino por recorrer}

Aunque el retrato de Estalella se explica en buena medida por el afecto fraguado entre suegro y yerno, Mir pintó el rincón de los juguetes llevado por un sentimiento más recóndito. Hay melancolía en la paleta del pintor catalán, como la hay en la pluma de 
Novalis, de Hölderlin, de Baudelaire y de Victor Hugo cuando loan al juguete. Todos ellos parecen añorar su infancia (Vaz-Romero, 2011). En el cuadro de Mir, el caballito de cartón, las muñecas y los cochecitos de madera son luces de nostalgia que atenúan la oscuridad de la estancia. Una emoción así apenas encuentra parangón en los óleos del pintor catalán. Pero el lienzo resulta más elocuente, si cabe, al comprobar que es también una de las pocas representaciones pictóricas de una juguetería en toda la historia del arte español, más aún de una época anterior a la Guerra Civil. Sólo la mirada de la ilustradora Lola Anglada Sarriera (1896-1985) parece salirle al encuentro.

Como le ocurrió a Mir, Anglada se conviritó durante algunos años en una meticulosa etnógrafa de su ciudad natal (Castillo, 2000: 152-154). Los dibujos fueron encargados por el historiador Francesc Curet para iluminar la obra titulada Visions barcelonines, un estudio de la Barcelona decimonónica publicado en diez tomos por la editorial Dalmau i Jover entre 1952 y 1958. En el volumen dedicado al comercio, la ilustradora delinea una juguetería semejante a la de Estalella [fig. 6]. De hecho, la disposición de los objetos no dista mucho de la que hubiésemos encontrado en el Brazalete Moderno: figuritas de feria, pelotas y juegos de destreza, trenes junto a una preciosa Arca de Noé, un muñeco de Pinocho - un anacronismo de Anglada, pues la obra de Collodi sólo llegó a España en 1900 - una ristra de muñecas con sus vistosos carritos y un lujoso caballo-triciclo como el que había pintado Joaquim Mir.

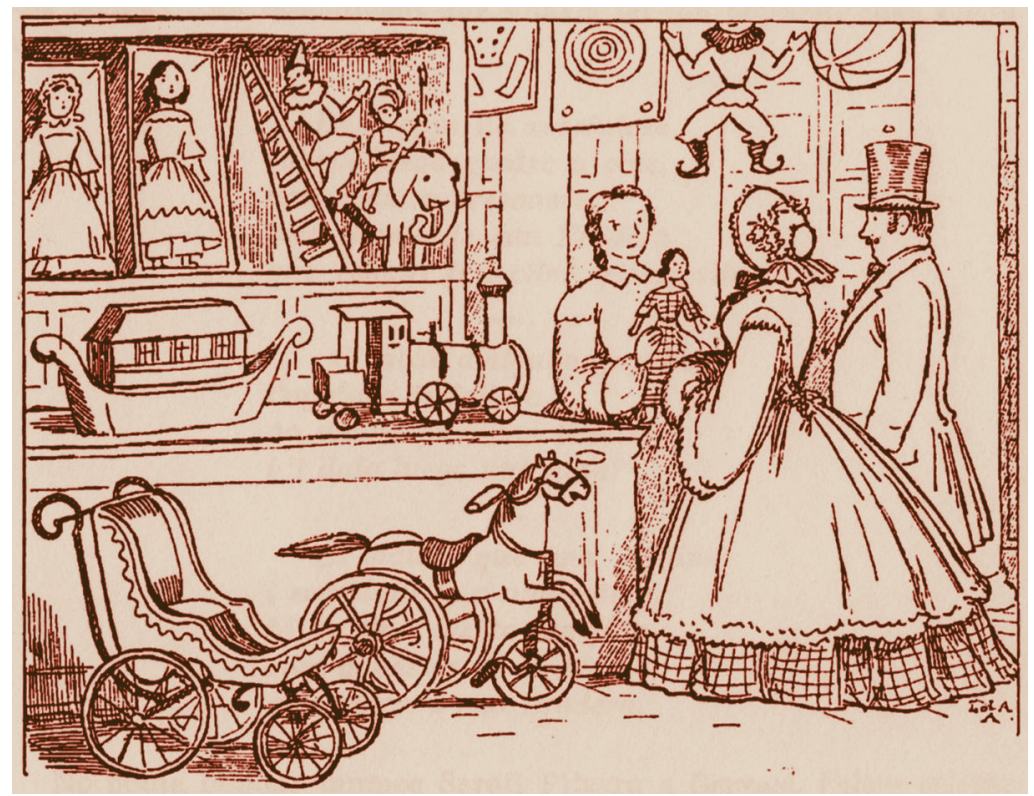

Figura 6.

El capítulo dedicado a los juegos de la infancia describe el funcionamiento de la industria, los vendedores ambulantes, las ferias y el nacimiento de los diferentes comercios que agrupaban la producción juguetera barcelonesa. Las etapas descritas por Curet son en todo coincidentes con las del contexto vilanovino (Curet, 1954: 219-38). 
Durante la segunda mitad del siglo XIX, cada gremio seguía produciendo un tipo de juguete en particular o bien sus complementos respectivos. Poco difería esta realidad del modelo medieval. Los herreros fabricaban figuritas de estaño; los torneros y ebanistas se encargaban de las muñecas articuladas; los hojalateros hacían lo propio generando toda clase de ingenios y criaturas mecánicas; también competían con los cesteros, lampistas y grabadores. Estos últimos poseían el monopolio de las estampas, cromos y hojas de Aleluyas, como las de Faustino Paluzié. Pero cada uno vendía celosamente sus productos y evitaba invadir territorio ajeno. No fue hasta la década de 1870 cuando los habitantes de Madrid y Barcelona, como los de Vilanova y la Geltrú, comenzaron a contar con comercios capaces de centralizar la venta de todos aquellos artículos infantiles que procedían tanto de los distintos oficios manuales como de las nacientes industrias jugueteras de Ibi, Denia, Onil, Pamplona, Murcia, Eibar, Madrid, Valencia, Zaragoza y Barcelona. A menudo, los propietarios de estas quincallerías eran extranjeros, por lo que solían importar además muñecas de París, Sajonia, Turingia, Baviera y Londres, cuya mirada vítrea tanto inquietaba a Apollinaire (Apollinaire, 1993). Las muñecas dibujadas por Lola Anglada pertenecen a esta última categoría, así como las de su propia colección, hoy conservada en Can Llopis, el Museo Romántico de Sitges (Anglada, 1983. Gou Vernet, 1986).

A finales de 1880, las quincallerías empezaron a vender juguetes mecánicos, como los que recuerda Manuel Vázquez Montalbán en su célebre diatriba periodística titulada La noche de los juguetes vivientes (1973). Entre los quincalleros barceloneses más reputados cabe recordar a Agustí Feliu Miralles, propietario del Pasaje de las Columnas, a Llorenç Fradera y a Miró Guadall Aduà, con su "grande y extraordinaria exposición de juguetes y otros objetos de utilidad y fantasía en el antiguo y acreditado establecimiento de quincalla A la Villa de Madrid, calle de Fernando VII, 44" (Dinastía, 1884). Luego vino el triunfo de los almacenes El Siglo y El Globo, situado este último entre la Rambla y calle Pelayo (Curet, 1954: 234-235). En vísperas de Reyes, anunciaban a toda página sus célebres paradas de juguetes. Estas campañas fueron emuladas por las quincallerías La Dalia Azul, la tienda de la Plaza Real y los ya citados almacenes de Guadall (Corredor-Matheos, 1981: 60-62). Este nuevo panorama comercial no había hecho más que empezar, poniendo en juego a un nuevo actor del siglo XX: el niño consumidor.

Por paradójico que resulte, el auge de estos establecimientos — que podemos situar entre 1880 y 1914 y cuya historia merecería estudio aparte - se estrella con la escasa repercusión que tuvo en los artistas del momento. Exceptuando algún posible dibujo publicado en prensa, el lienzo de Mir y las ilustraciones de Anglada permanecen como uno de los escasos testimonios artísticos de las antiguas jugueterías españolas. No ocurre lo mismo en el ámbito francés ni en el anglosajón, entre los que despuntan imágenes de gran belleza y expresividad, unidas a los imaginarios mágicos y los cuentos de hadas. Al llegar a este punto, parece que nuestro ejercicio unamuniano ha llegado a buen puerto. Sin apenas darnos cuenta, una simple pintura nos ha conducido más allá de la vida del retratado y de su tienda, elevándonos hacia las costumbres de una ciudad, de una época, situándonos al fin ante un horizonte más amplio: la historia de las jugueterías en Europa y su aparición en el arte moderno. Este es un camino apenas transitado, que nos quedará por recorrer. Pero al menos este ejercicio de microhistoria ha demostrado que lo pequeño encierra a menudo un « fondo eterno » que merece ser descubierto. 


\section{Referencias}

Albalate, L. (1993). Cap de Creus. Valencia: Ángeles.

Aliberch, R. (1957, 20 de febrero). La juguetería catalana. Riqueza. Revista de información económica y financiera, 693, 5-6.

Anglada, L. (1983). Les meves nines. Barcelona: Alta Fulla.

Apollinaire, G. (1993). Jouets d'enfants. En Décaudin, M. \& Caizergues, P. (Ed.), Apollinaire. Euvres en prose complètes (p. 536). Paris: Gallimard.

Azorín (1922, 28 de diciembre). La esperanza sobre el pesimismo, crítica de la novela "El amor, el dandismo y la intriga" de Pío Baroja. $A B C, 6234,3$.

Balaguer (1901, marzo-abril). Monumento a Balaguer. Boletín de la Biblioteca-Museo Balaguer. Revista mensual, 14-15, 1-2.

Barral, C. (2001). Memorias. Barcelona: Península.

Baudelaire, Ch. (2005). La moral del juguete. Salones y otros escritos sobre arte (pp. 189-196). Madrid: La Balsa de la Medusa.

Bolòs, J. (2000). Diccionari de la Catalunya medieval, ss. VI-XV. Barcelona: Ed. 62.

Carrera Pujal, J. (1961). La economía de Cataluña en el siglo XIX. Barcelona: Bosch.

Borràs, M. L. (1993). Enric C. Ricart. De la pintura al gravat. Vilanova y la Geltrú: Biblioteca-Museu Víctor Balaguer.

Castillo, M. (2000). Lola Anglada o la creació del paradís propi. Barcelona: Meteora.

Corredor-Matheos, J. (1981). La Joguina a Catalunya. Barcelona: Ed. 62.

Cruells, M. (1994). Joaquim Mir pinta figures a Mollet. Notes (8), 61-65.

Curet, F. (1954). Visions Barcelonines, 1760-1860. Botigues, obradors $i$ cases de menjar $i$ beure. Barcelona: Dalmau i Jover.

Defensa (1927, 17 de febrero). N'Antoni Estalella Trinxet. La Defensa, 98, 1-2.

Diario de Vilanova (2003, 1 de agosto). Diari de Vilanova, 26271, 123-128.

Dinastía (1884, 1-5 de enero). La Dinastía (116-123), 3, 27, 51, 99.

Engel, A. (1892). Rapport sur une mission archéologique en Espagne (1891). Nouvelles Archives des Missions scientifiques et littéraires (t.3, pp. 111-219). París: Leroux.

Estalella Trinxet, A. (1921). Antoni Estalella a Joaquim Mir, Vilanova, 1921. En: Fondo Joaquim Mir Ms. 4402/4. Barcelona: Biblioteca de Catalunya.

Fomento (1907, febrero). Fomento del Trabajo de Villanueva y Geltrú, 10, 25.

Fontbona, F. (1999). El Romanticisme a Catalunya 1820-1874. Barcelona: Pòrtic.

Gou Vernet, A. (1986). Les Nines del Museu Romàntic. Barcelona: Diputación.

Jardí, E. (1975). J. Mir. Barcelona: Polígrafa.

Jardí, E. (1989). Joaquim Mir. Barcelona: Polígrafa.

Jutglar, A. (1976). Pi y Margall y el federalismo español. Madrid: Taurus.

Llorens Artigas, J. (1918, 13 de agosto). El Castell de la Geltrú. La Veu de Catalunya, 6964, 9.

Mam (1972). Exposición Joaquín Mir (1873-1940). Barcelona: Ajuntament de Barcelona.

Manson, M. (2005). Histoire du jouet dans l'art. Annali della Facoltà di Lettere e Filosofia, 26-27. Siena: Cadmo, 129-164.

Martín Gaite, C. (1987). El arreglo a hurtadillas. Usos amorosos de la postguerra española (pp. 121-122). Barcelona: Anagrama.

Mas Perera, P. (1932). Vilafranca del Penedès. Barcelona: Barcino. 
Massanell Esclassans, A. (1984). Notícia sobre els boters vilafranquins. Miscel-lània Penedesenca (pp. 199-236). Vilafranca: Institut d'Estudis Penedesencs.

Mestre, V. (1999). Les manufactures artístiques durant el Romanticisme. En Fontbona, F. \& Jorbà, M. (Ed.), El Romanticisme a Catalunya (pp. 94-98). Barcelona: Pòrtic.

Mir, J. (1934). Llibre o arxiu de les belles amistats que passen per nostra casa (libro de firmas autógrafas y dedicatorias a Joaquim Mir y a su familia, del 15-VI-1934 a los años 1989, 1994 y 2001). Ms. 4529. Barcelona: Biblioteca de Catalunya.

Miralles, F. (2006). Joaquim Mir a Vilanova. Vilanova i la Geltrú: Viena.

Miralles, F. (2007). Joaquim Mir a Vilanova. Quaderns de Patrimoni del Garraf (6), $19-22$.

Ortiz Domènech, X. (1988). Aproximació a l'estructura comercial vilanovina a la segona meitat del segle XVIII. Miscel-lània penedesenca (12), 33-46.

Pérez Valiente, S. (1946, diciembre). Juguetes para pobres. Revista de las artes y los oficios: arte y oficio de la juguetería (31), 18-19.

Pi de Cabanyes, O. (2006). Joaquim Mir a Vilanova. En Miralles, F. (Ed.), Joaquim Mir a Vilanova (pp. 44-54). Vilanova y la Geltrú: Viena.

Pi y Margall, F. (1895, 26 de enero). Una carta prólogo. El Nuevo Régimen, 212, 3.

Pla, J. (1996). El pintor Joaquim Mir. Barcelona: Destino.

Puig Rovira, F. X. (2003). Diccionari biogràfic de Vilanova i la Geltrú. Vilanova y la Geltrú: El Cep i la Nansa.

Puig Rovira, F. X. (2005). Vilanova i la Geltrú 1936-1939. Barcelona: Publicacions de l'Abadia de Montserrat.

Puig Rovira, F. X. (2006). Joaquim Mir, Vilanova, 1922. En Miralles, F. (Ed.), Joaquim Mir a Vilanova (pp. 35.43).Vilanova y la Geltrú: Viena.

Puig Rovira, F. X. (2011). Personatges singulars: Cristòfol Escofet Roset. Butlletí de la Biblioteca-Museu Victor Balaguer, 4, 170-173.

Ricart Nin, E.-C. (1922, 20 de junio): Quadern Kodak I. Vilanova y la Geltrú: BibliotecaMuseu Víctor Balaguer, 1 fol. r.

Salvat-Papasseit, J. (1982). Pantalons llargs. Poesia: L'irradiador del port i les gavines (p. 40). Barcelona: Península-Ed. 62.

Serra Pagès, R. (1926). Alguns escrits del professor, col-leccionats i publicats en honor del Mestre..., 1875-1925. Barcelona: Casa Miquel-Rius.

Targa Chicano, E. A. \& Barbacil Mestre, J. (2006). D'Abans i d'Ara: jocs, joguines $i$ cançons. Vilanova y la Geltrú: Ajuntament de Vilanova i la Geltrú.

Unamuno, M. (1967). En torno al casticismo. Obras completas: Paisajes y ensayos (t. 1, pp. 773-869). Madrid: Escelicer.

Vaz-Romero Trueba, O. (2011). El juguete en el Romanticismo y sus aledaños. El artista y el juguete: viajes al imaginario occidental, desde la Antigüedad al Romanticismo. (Tesis inédita de doctorado). Université Paris-XIII, París, t. 3, 1623-1964.

Veu (1921, 29 de julio). L'estany de Foix. La Veu de Catalunya, 7931, 9.

Veu (1927, 22 de febrero). La catedral penedesenca. La Veu de Catalunya, 9588, 4. Virella Bloda, A. (1978). De quan Vilanova i la Geltrú era un empori del vi. Miscel·lània penedesenca, 205-240. 